\title{
Impact of temperature and fermentation period on the overall quality of black tea
}

\author{
Said Wahab ${ }^{1}$, Fahim Ullah ${ }^{2,3 *}$, Mansoor Khan $\mathrm{Khattak}^{3}$, Muhammad \\ Sohail Memon ${ }^{2}$ and Lubna Hassan ${ }^{4}$
}

1. Department of Food Science and Technology, The University of Agriculture, Khyber Pakhtunkhwa, Peshawar-

Pakistan

2. College of Engineering, Nanjing Agricultural University, Nanjing, 210031, P.R. China

3. Department of Agricultural Mechanization, The University of Agriculture, The University of Agriculture, Khyber Pakhtunkhwa, Peshawar-Pakistan

4. Department of Zoology, Kohat University of Science \& Technology, Khyber Pakhtunkhwa-Pakistan

*Corresponding author's email: fahimullah320@yahoo.com

Citation

Said Wahab, Fahim Ullah, Mansoor Khan Khattak, Muhammad Sohail Memon and Lubna Hassan. Impact of temperature and fermentation period on the overall quality of black tea. Pure and Applied Biology. Vol. 5, Issue 4, pp1278-1287. http://dx.doi.org/10.19045/bspab.2016.50153

\begin{tabular}{llll}
\hline Received: 02/06/2016 & Revised: 10/09/2016 & Accepted: 11/10/2016 & Online First: 02/12/2016 \\
\hline
\end{tabular}

\section{Abstract}

Black tea processing fermentation was studied at different temperatures and times. Time and temperature have a significant effect on the aflavin content of black tea. Highest mean percentage of the aflavin $(0.53 \%)$ was recorded at $20-210 \mathrm{C}$ while the lowest percentage $(0.41 \%)$ was seen at 28-29 0C. Significant effect was also found on the the arubigens where maximum mean value (17.36\%) was found at 180 minutes and minimum (15.97\%) at 100 minute. Time and temperature have a significant effect on TSS. Maximum mean value $(36.47 \%)$ was recorded at 120 minutes and minimum (33.90\%) at 180 minute. On caffeine and acidity, there was no significant effect of time and temperature. However, the significant effect was found on quality, hue and thickness. For quality, maximum mean score (4.52) was noticed at 100 minute and minimum (4.22) at 180 minute at 20-21 0C highest mean score (4.57) and the lowest score (4.28) at 28-29 0C was observed. Maximum and minimum mean hue score was (4.43) and (4.06) at 120 minutes and 100 minutes respectively. While at 28-29 0C highest mean scores (4.53) and lowest, score (3.99) at 24-25 0C was recorded. Maximum mean score (3.94) and minimum (3.78) were found in thickness at 120 minutes and 180 minute respectively. At 20-21 0C high mean scores of (3.93) and a low score of (3.76) at 28-29 0C was observed.

Keywords: Temperature; Fermentation period; Quality; Black tea; Total Soluble Solid; Acidity

\section{Introduction}

Black Tea, botanical name is Camellia sinensis. $L$. belongs to family the aceae, and is a perennial herbaceous and dicotyledonous crop [1]. In ancient China tea was originally known for its medicinal properties [2]. The medicinal use of tea is recorded in medical book of the Tang
Dynasty (618-609 AD) where it was noted that it has disease curing and detoxicating activity (Chen) with the expansion of tea cultivation and development of the processing technique, tea became a popular beverage in China and was considered a symbol of social status and civilization. Gradually the practice of tea drinking spread 
throughout the world $[3,2]$. The origin of tea is China and its regular drinking began there in 16 th century A.D $[4,5]$. It spread to Japan in 1000 AD and by the middle of the 17 th century; black tea has become popular in Europe. In the middle of 18th century, British started black tea cultivation in India and other colonies $[6,7]$. The Indians (South East, Sub-Continent) got familiar to tea due to British rule in 18th century [8]. The main tea producing countries are India, China, Srilanka, Indonesia, Turkey, Japan, Vietnam, Bangladesh, and Argentina whereas exporting countries are Srilanka, Kenya, China, India, Indonesia, Vietnam, Argentina, Malawi, Uganda and Tanzania $[2,9,6]$. Major tea importing countries is Russia, UK, Pakistan, USA, Egypt, Japan, Iraq, Morocco, Iran and Poland [8, 10].

Tea is a traditional beverage of Pakistan and per capita consumption is $1 \mathrm{~kg}$ per annum. Pakistan imports its entire black tea requirement "from abroad and thus, the total annual import of black tea was 2, $60000 \mathrm{~m}$ tons in 2000 worth Rs.12 billion [11-13]. Presently Pakistan is the 2nd largest importer of black tea. Demand for black tea is growing day by day and in the wake of high growth rate of population $(3.1 \%$ annually); Pakistan is likely to become the world largest importer of black tea by the year 2010" [1, 4, 11]. Although the climatic conditions of Pakistan are not $100 \%$ fit for tea cultivation yet the prospective teas growing areas in Pakistan are located in Hazara and Swat in Khyber Pukhtunkhwa lying around $34.8219^{\circ} \mathrm{N}$ latitude and $72.1854^{\circ} \mathrm{E}$ longitude in a contiguous belt in the foot hills of Himalayas and Hindukush [11]. The period from December to March is coldest with air temperature ranging from $0.12{ }^{\circ} \mathrm{C}$ causing the arrest of vegetative growth of the plants. With the onset of spring, the growth starts in April and continued through the summer till autumn.
Tea cultivation started for the first time in Pakistan in 1958 at village Baffa (Distt. Mansehra) under the auspices of Pakistan Tea Board. The 2nd attempt was made in 1964 and a pilot project "Irrigated Tea Plantation" was initiated by the West Pakistan Agricultural Development Corporation at Misriot Dam near Rawalpindi. The National Tea research institute was established in 1984 at Shinkiari, District Mansehra under Pakistan Agricultural Research Council Islamabad. Chinese experts visited the prospective tea growing areas in 1988 and submitted a comprehensive report on the economic feasibility of tea cultivation in Pakistan [11]. Unilever Pakistan Limited (UPL) on its own started a parallel exercise in 1987. Unilever concluded after research that although conditions for black tea growing in Pakistan are not ideal yet tea can be grown in Hazara and swat region. In 1989, Unilever established a small and well equipped tea research station on 9 acres of land at Shinkiari in Mansehra. After ten years of research, Unilever established first modern CTC (Cut, Tear, Curl) tea processing plant in Pakistan near Dhodial (Mansehra) in 2001 inaugurated by the President of Pakistan General Pervez Musharraf. In Pakistan tea has been cultivated in Distt. Mansehra, Battagram and Abbottabad mostly by Unilever Pakistan limited spending millions of rupees with attractive incentives to farmer's i.e. young tea plants are provided to the farmers free of cost along with free fertilizers, acidifying chemicals and expertise $[4,10,13]$.

National tea research institute Shinkiari (Mansehra) under PARC (Pakistan Agricultural Research Council) has also planted tea on a small area in Distt. Mansehra, Battagram and Swat. Processing Plant has been established with the help of China on NTRI, Shinkiari Mansehra. 
Tea plant requires all those factors, which are essential for other plants growth. The climate, soil structure and $\mathrm{pH}$ are the important factors responsible for its growth. Ta requires $1000-1500 \mathrm{~mm}$ evenly distributed rainfall annually and air temperature, ranging from $20^{\circ} \mathrm{C}-30^{\circ} \mathrm{C}$ for optimum growth. Well drained plain and sloppy lands can be successfully exploited for tea cultivation. Tea is cultivated in a sandy loam soil and requires acidic soil having $\mathrm{pH} 4.5$ to $5.5[1,5,8]$. The flavor and quality vary with the soil, climate and age of the leaf, time of plucking and method of preparation [3]. The international standard for plucking is two leaves and a bud but in Pakistan due to marginal condition we take three leaves and a bud. Soluble solids measurement is a good indicator of the potential mouth feel and thickness of black tea liquor [1].

Research conducted on tea for its medicinal value shows that it contains stress fighting vitamin $\mathrm{C}$, antioxidant vitamin $\mathrm{E}$ a disease fighting vitamin $\mathrm{A}$ it contains catching a chemical compound, said to kill bacteria and viruses $[4,5]$. It acts as a blood thinner and inhibits blood platelets clumping together, a major factor in depositing cholesterol in blood vessels [14, 15]. Tea is good for diabetes as it contains polyphenols, which help in preventing too much sugar from absorbing in the blood pressure. Tea prevents colon cancer in particular and may shrink existing cancers and stop them from spreading to other parts of the body [3]. Tea as a beverage either black or green is considered as a traditional beverage in Pakistan and particularly in Khyber Pukhtunkhwa. This study was designed to find out how the fermentation time and temperature influences the chemical composition and organoleptic characteristics of black tea. The study will be helpful for tea processors and ultimately to the end users.

\section{Methods and materials}

The present research work was carried out in Unilever tea processing plant Dhodial. Black tea is manufactured from fresh leaves. Leaves were taken from tea gardens and brought in the tea processing unit on the factory. After withering, crushing the leaves were cut, tea red and curled in 4 sets of CutTear-Curl (CTC) machine to get the desired size. Fermentation was carried out by enzyme polyphenols oxidize; the leaves were dried in fluid bed drier to reduce the moisture content. After grading and sorting of tea particles the made tea was packed in aluminum coated sacks.

\section{Results \\ The aflavin}

The aflavin is considered to be the responsible for color developed during fermentation. Results regarding the aflavin content are presented in Figure 1. The highest the aflavin was noticed on $20-21^{\circ} \mathrm{C}$ at 180 minutes of fermentation time. While the minimum value of the aflavin $0.35 \%$ was noticed for 180 minutes at $28-29^{\circ} \mathrm{C}$ temperatures. Statistical analysis revealed that both time and temperature have a significant influence $(\mathrm{P}<0.01)$ on the aflavin content of black tea. The maximum mean value is $0.48 \%$ was recorded for 180 minutes of fermentation time followed by $0.47 \%$ at 100 and 160 minutes respectively. While the minimum value of $0.46 \%$ was observed at $28-29^{\circ} \mathrm{C}$. The highest percentage of the aflavin 0.53 was recorded at $20-21^{\circ} \mathrm{C}$ followed by 0.47 at $24-25^{\circ} \mathrm{C}$, while the minimum value $0.41 \%$ was observed at $28-29^{\circ} \mathrm{C}$. The interaction of fermentation time and temperature has significant effect on the aflavin content. From these findings it is indicated that increasing the fermentation temperature lowering the the aflavin content. 
Wahab et al.

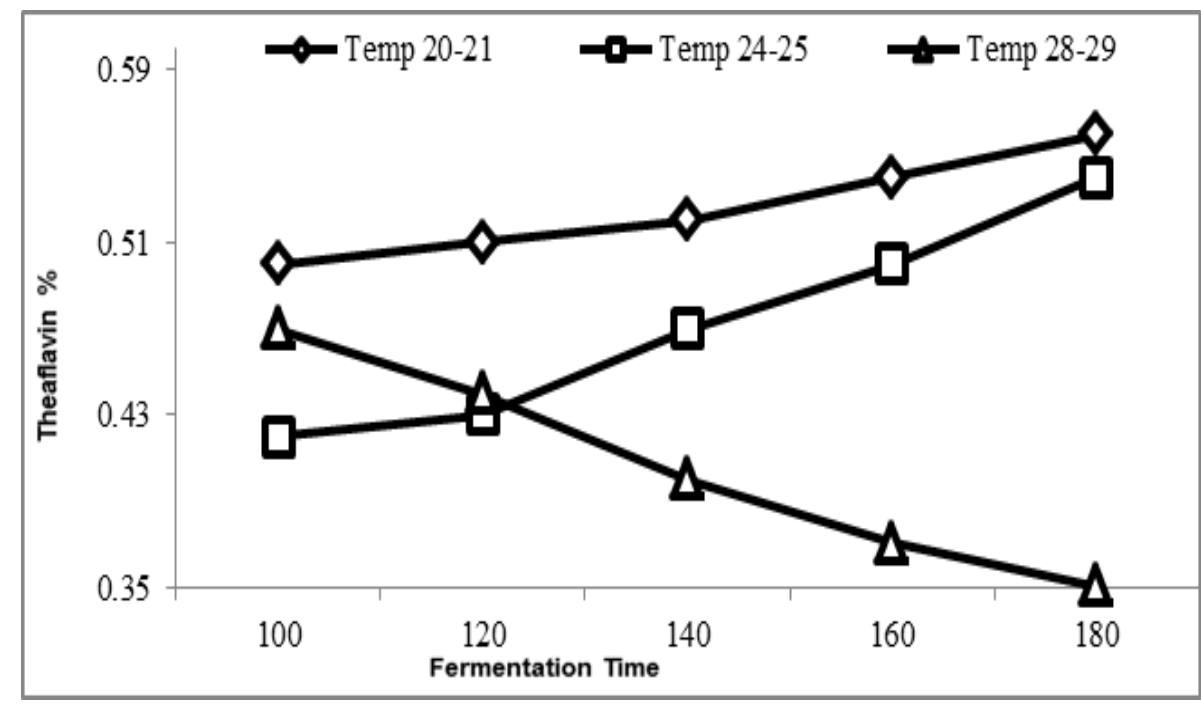

Figure 1. Influence of fermentation temperature and duration on theaflavin Content in black tea

\section{The arubigens}

Reddish brown the arubigens are responsible for the color of made tea. The arubigens are formed during the fermentation process, which largely depends upon fermentation time and temperature. The influence of fermentation time and temperature is presented in Figure 2. The maximum percentage of the arubigens was observed $17.45 \%$ on 180 minutes at $24-25^{\circ} \mathrm{C}$ while the minimum value of $15.53 \%$ was noticed on 100 minutes of fermentation at $28-29 \mathrm{C}$. Statistical analysis showed that maximum mean value was $17.36 \%$ at 180 minutes followed by $16.28 \%, 16.44 \%, 16.64 \%$ at 120,140 and 160 minutes respectively, while the minimum value was recorded $15.97 \%$ at 100 minutes. The highest mean value was observed $17.01 \%$ at $24-25^{\circ} \mathrm{C}$ followed by $16.35 \%$ at $20-21^{\circ} \mathrm{C}$ and the lowest value was recorded $16.25 \%$ at 28 $29^{\circ} \mathrm{C}$. The interaction between fermentation time and temperature was found nonsignificant with respect to the arubigens contents. From these results, it is indicated that by increasing fermentation temperature lowering the the arubigens content.

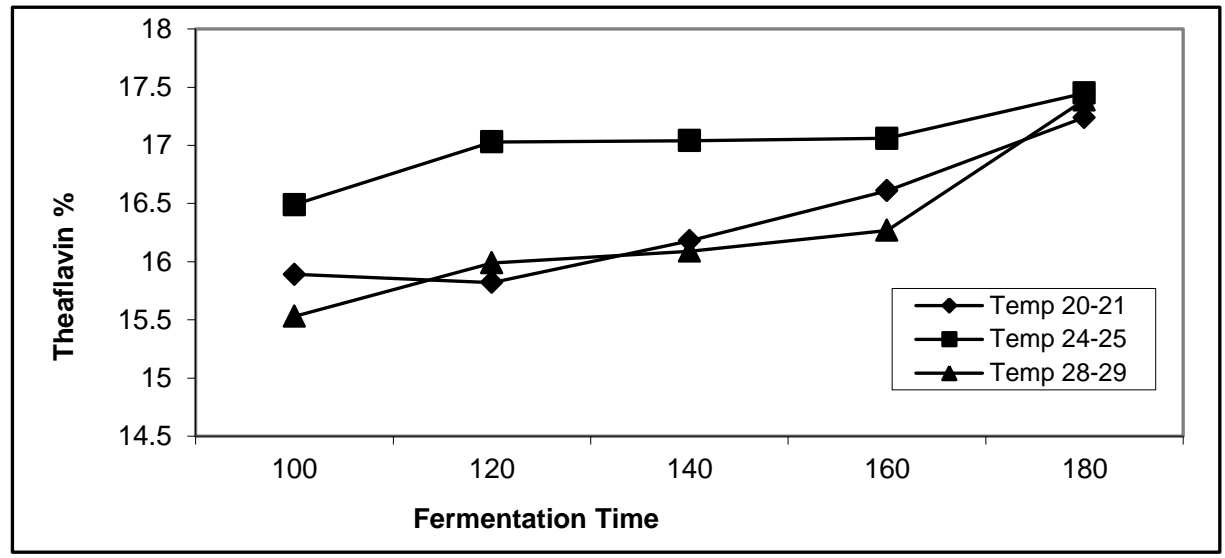

Figure 2. Influence of fermentation temperature and duration on Thearubigens content in black tea 


\section{Total soluble solids}

Thickness is an important attribute of black tea and depends upon amount of TSS present. TSS include TF, TR. Increase in these contents with an increase in TSS then more will be its thickness and better will be the mouth feel. Results regarding TSS content are presented in Figure 3. The amount of TSS was determined at different time and temperature to get good quality black tea. The highest value of TSS $38.72 \%$ was recorded on 120 minutes at $20-21{ }^{\circ} \mathrm{C}$ while the minimum value of $32.93 \%$ was observed on 160 minutes at $28-29^{\circ} \mathrm{C}$. Statistical analysis revealed that both fermentation time and temperature have a significant influence $(\mathrm{P}<0.01)$ on TSS content of black tea. The Maximum mean value was $36.47 \%$ and $36.07 \%$ at 120 and 100 minutes of fermentation followed by $35.86 \%$ and $35.11 \%$ at 140 and 160 minutes respectively. The highest mean value of TSS was recorded $37.45 \%$ at $20-21^{\circ} \mathrm{C}$ followed by 34.79 at $28-29^{\circ} \mathrm{C}$ and lowest value 34.20 was observed at $24-25^{\circ} \mathrm{C}$. From the result it is clear that the interaction between fermentation period and temperature have significant effect.
Caffeine contributes briskness of black tea. The extent of cream formation is largely dependent on the amount of caffeine present in tea. It is colorless and contributed to pungency moderate intake of caffeine is beneficial for good functioning of nerves system. The influence of fermentation time and temperature on caffeine contents is presented in Figure 4. Maximum value of caffeine $2.35 \%$ was recorded at 140 minutes at $28-29^{\circ} \mathrm{C}$. While the lowest value of $2.31 \%$ was noticed about 100, 140, 160 minutes at $24-25^{\circ} \mathrm{C}$ temperature. Statistical analysis revealed that both time and temperature have a non- significant influence on caffeine contents of black tea. The maximum mean value is $2.32 \%$ was recorded at 100 to 120 and 140 minutes. While the lowest mean value was recorded $2.31 \%$ on 160 and 180 minutes. The highest mean value 2.32 was recorded at $20-21^{\circ} \mathrm{C}$ and $28-29^{\circ} \mathrm{C}$ and the lowest was observed 2.31 at $24-25^{\circ} \mathrm{C}$. The result showed that the interaction between fermentation period and temperature has non-significant effect on caffeine contents.

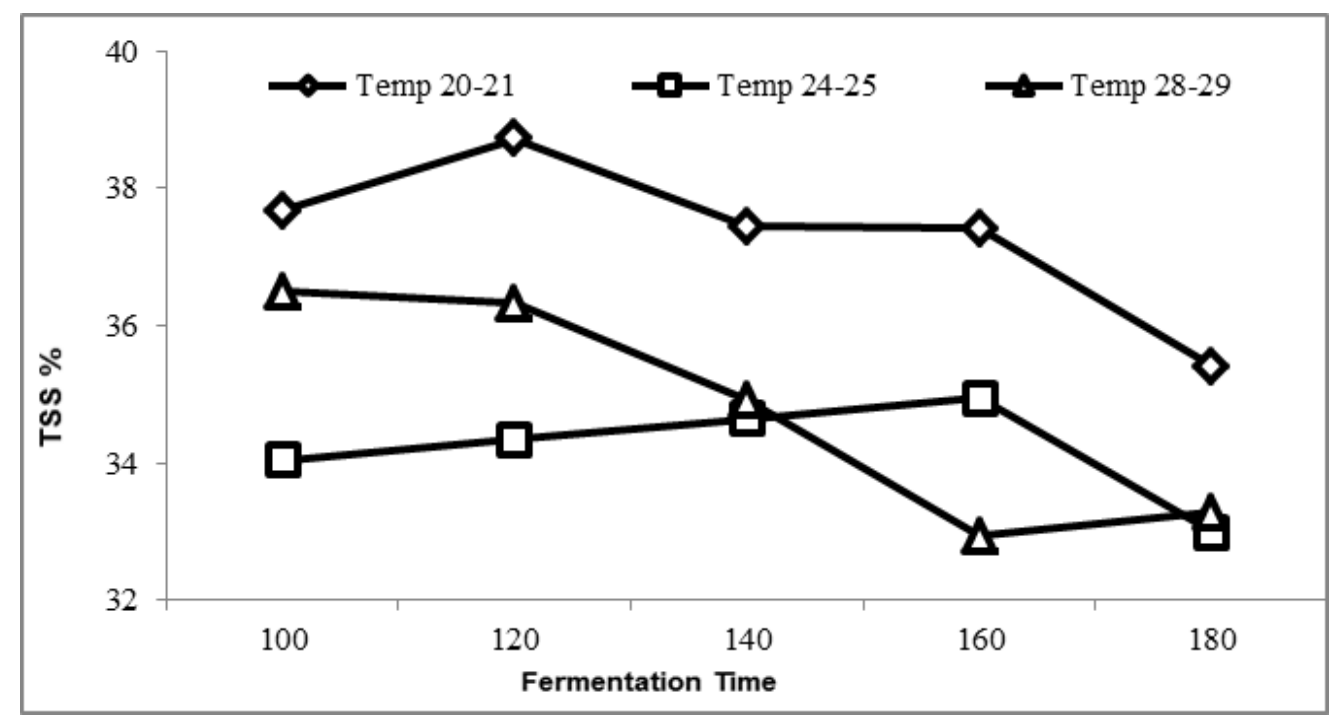

Figure 3. Influence of fermentation temperature and duration on TSS content in black tea Caffeine 


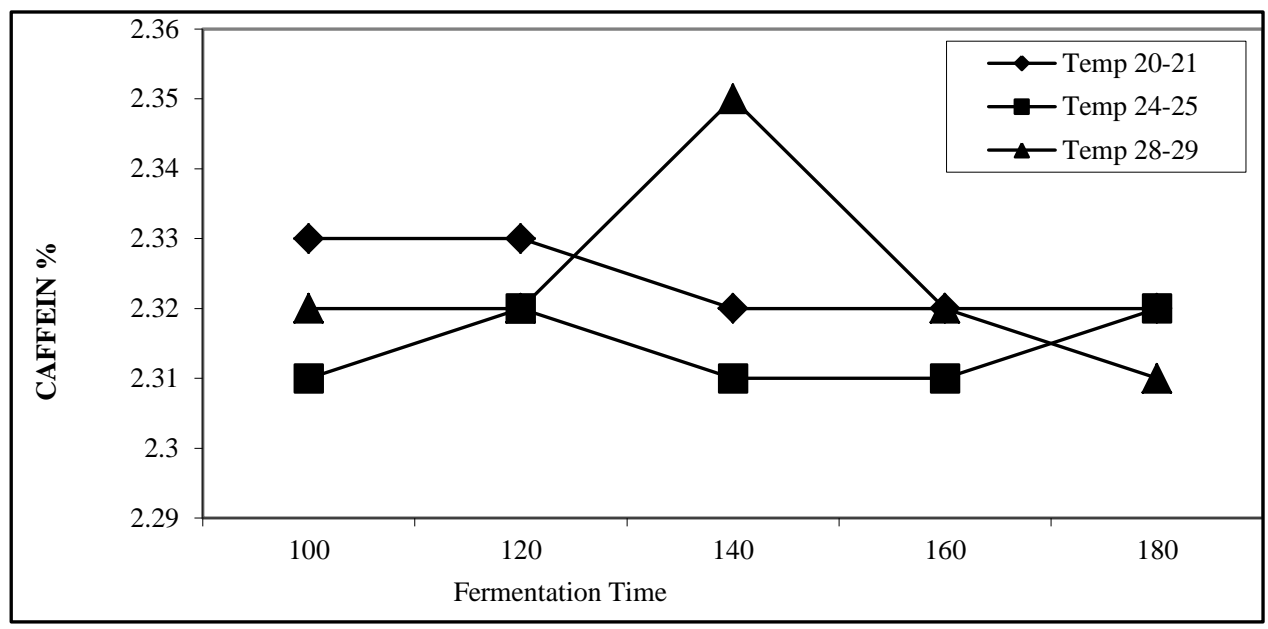

Figure 4. Influence of fermentation temperature and duration on Caffeine content in black tea

\section{Acidity}

Acid is the by-product of any fermentation process in tea, during this process linolenic, aldehyde are formed due to which tea is acidic in nature. Results regarding acidity content are presented in Figure 5. The maximum value of $5.43 \%$ was noticed in 160 minutes at $24-25^{\circ} \mathrm{C}$. While the lowest value of $5.28 \%$ was observed at 180 minutes at $28-29^{\circ} \mathrm{C}$ temperatures. Statistical analysis showed that both time and temperature have a non-significant effect on acidity of black tea. Maximum mean value was $5.38 \%$ at 160 minutes followed by $5.36 \%$ and $5.35 \%$ at 100 and 180 minutes of fermentation, while the minimum value of $5.34 \%$ was recorded at 120 and 140 minutes. The highest mean value is $5.36 \%$ was recorded at $24-25^{\circ} \mathrm{C}$ and $28-29^{\circ} \mathrm{C}$ followed by $5.35 \%$ at $20-21^{\circ} \mathrm{C}$. The result shows significant effect on acidity between fermentation period and temperature.

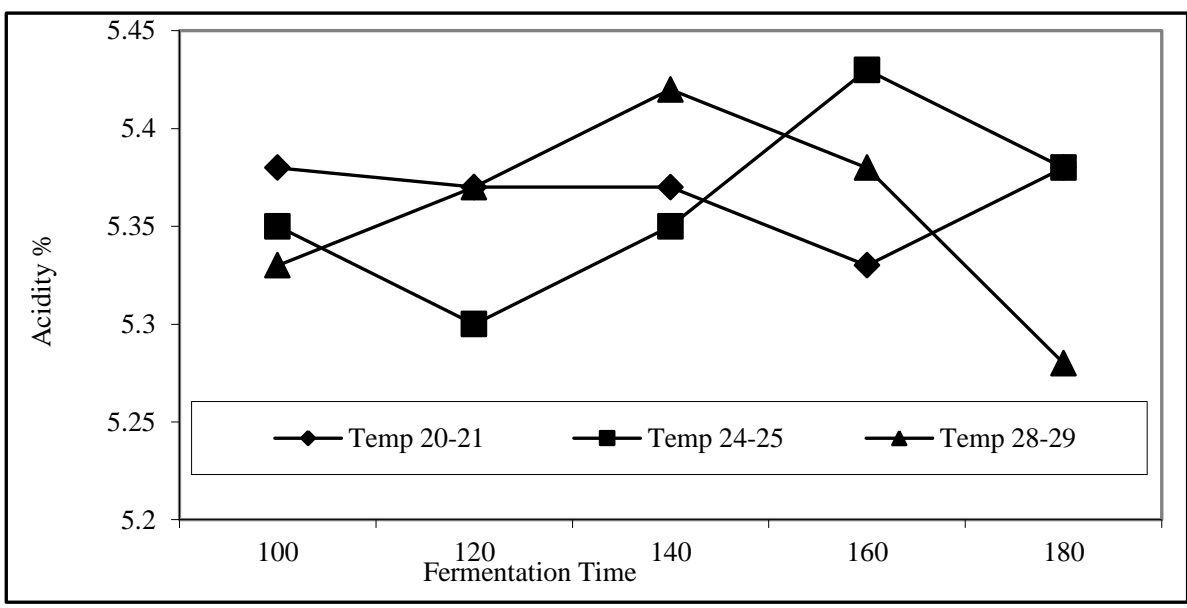

Figure 5. Influence of fermentation temperature and duration on Acidity

\section{Quality}

Quality shows the mouth feel and taste of black tea. Quality largely depends upon the presence of TF, TR and caffeine. With the increase of these contents, good quality of black tea will be processed. Quality of black tea is dependent on chemical components formed during the processing stage. These 
chemical components contribute liquor, color, brightness and taste of black tea. Physical and chemical withering also influences the taste and quality of black tea. The influence of fermentation time and temperature is shown in Figure 6. Results of the effect of different fermentation time and temperature on quality of black tea showed that the maximum mean value, 4.63 was recorded on 100 minutes at $20-21^{\circ} \mathrm{C}$ while the minimum value, 4.00 was observed at 180 minutes, at $24-25^{\circ} \mathrm{C}$. Statistical analysis revealed that both time and temperature have a significant influence $(\mathrm{P}<0.01)$ on quality of black tea. Maximum mean value was $4.52 \%$ at 100 minutes while minimum of $4.39 \%$ was recorded at 140 minutes. The highest mean value, 4.57 was recorded at 20 - $21^{\circ} \mathrm{C}$ followed by $4.34 \%$ at $24-25^{\circ} \mathrm{C}$ and the lowest was $4.28 \%$ observed at $28-290 \mathrm{C}$. They have a significant effect on quality due to the interaction between fermentation time and temperature.

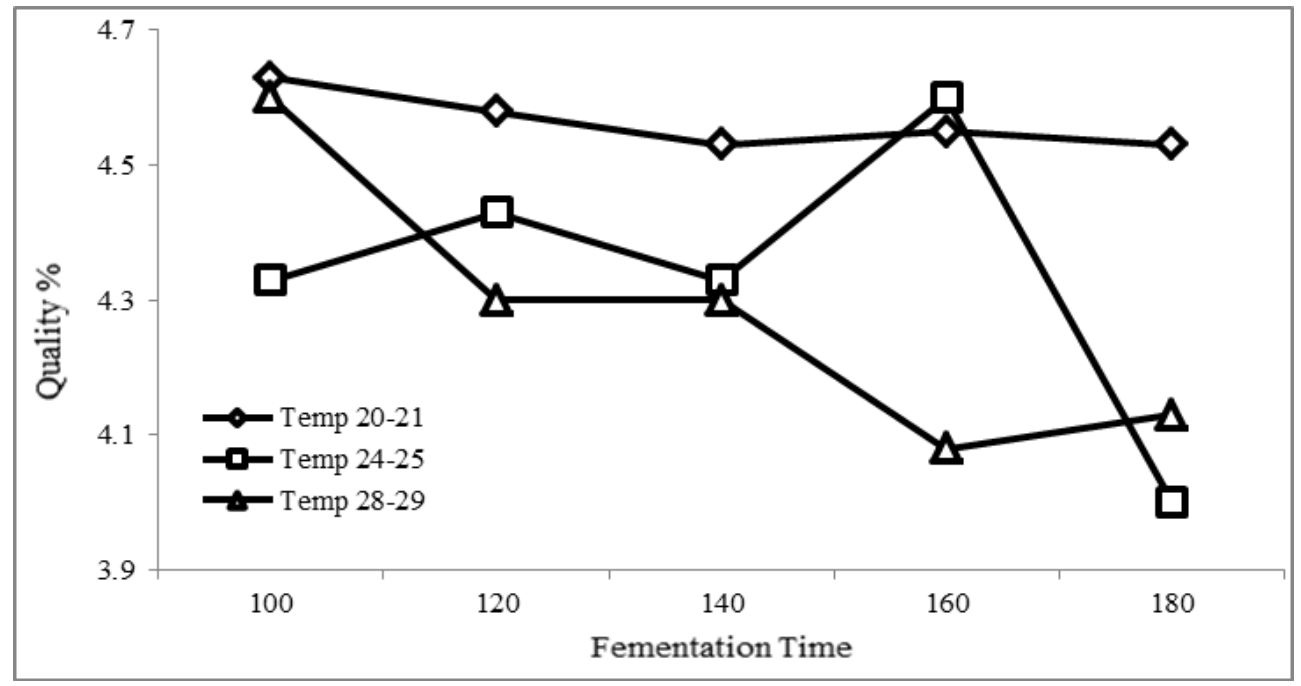

Figure 6. Influence of fermentation temperature and duration on Quality

\section{Hue}

Hue means color and as TF. TR are responsible for color thus, hue will be dependent on their presence. Results regarding TSS content are diagrammatically shown in Figure 7. Result pertaining to the influence of different fermentation times and temperature on hue of black tea. Highest value of $4.63 \%$ was noticed in 120 minutes at $20-21^{\circ} \mathrm{C}$. While the lowest of $3.77 \%$ was recorded at 160 minutes at $24-25^{\circ} \mathrm{C}$ temperature. The analysis of variance revealed that both time and temperature have a significant influence $(\mathrm{P}<0.01)$ on hue content of black tea. Maximum mean value is $4.43 \%$ in 120 minutes followed by $4.06 \%$, $4.14 \%, 4.22 \%$ at 100,140 and 180 minutes respectively while the lowest was $4.08 \%$, recorded at 160 minutes. The maximum mean percentage, $4.35 \%$ was observed at 28 - $29^{\circ} \mathrm{C}$ while the lowest hue value was recorded, $3.99 \%$ at $24-25^{\circ} \mathrm{C}$. 


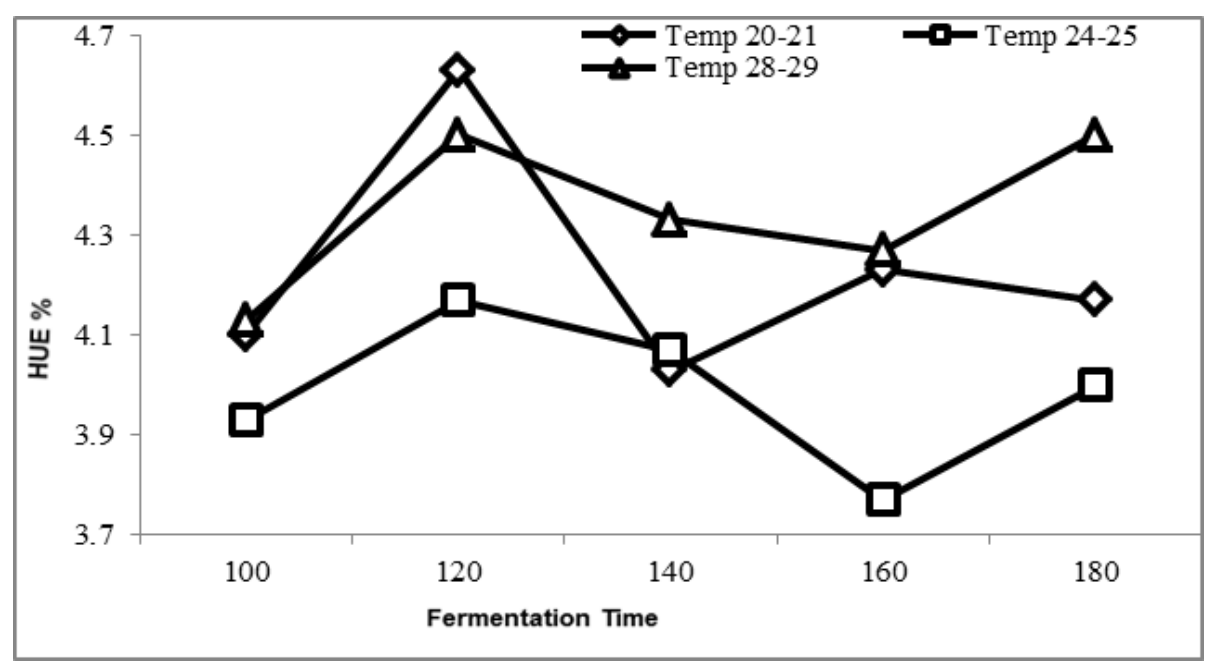

Figure 7. Influence of fermentation temperature and duration on Hue

\section{Thickness}

Thickness depends upon TSS, TF, TR and caffeine. The influence of fermentation time and temperature is presented in Figure 8. The maximum value $4.13 \%$ was observed at 120 minutes at $20-21{ }^{\circ} \mathrm{C}$. While the minimum value $3.60 \%$ at $28-29^{\circ} \mathrm{C}$ was recorded at 180 minutes of fermentation. The analysis of variance revealed that both time and temperature have significant influence on thickness of black tea. The maximum mean value is $3.94 \%$ was recorded at 120 minutes followed by $3.83 \%$, $3.84 \%$ at 100 and 140 minutes while the minimum value $3.78 \%$ was observed at 180 minutes of fermentation. The highest mean value of $3.93 \%$ was recorded at $20-21^{\circ} \mathrm{C}$ followed by $3.85 \%$ at $24-25^{\circ} \mathrm{C}$ and lowest value was $3.76 \%$ was found at $28-29^{\circ} \mathrm{C}$.

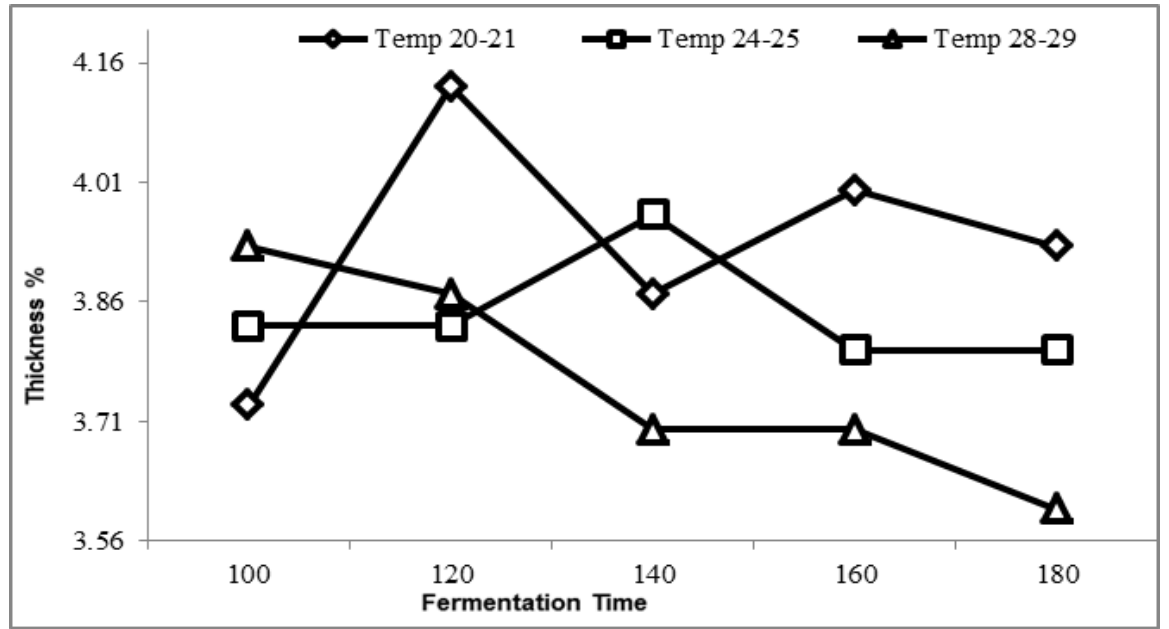

Figure 8. Influence of fermentation temperature and duration on Thickness

\section{Discussions}

Tea (C. sinensis) plants grown at In Tea Research garden were obtained to process the tea at various fermentation temperature and period. In the process of producing international standard tea, it has been recognized that there should be some chemical constituents whose presence in certain amounts ensure the quality of black tea. These constituents are the aflavin, the 
arubigens, TSS and caffeine. The influence of fermentation temperature and period on these constituents is presented in Figure 1-8. From these findings, it is indicated that increasing the fermentation temperature lowering the the aflavin content. These findings are in close contest of [14-16] that carried out research work on fermentation temperature and found that the low fermentation temperature improves black tea quality increasing fermentation temperature lowering the the arubigens content. Our results are in agreement with $[12,13,14,17]$ that carried out research work on quality parameters and found that fermentation duration and temperature have significant influence on the quality of tea. Low fermentation temperature black tea has higher levels of the arubigens and brightness. $[17,10,2]$ reported that processing of black tea at low fermentation temperature improved black tea quality. Long fermentation duration and low temperature favored production of more intensely colored black tea. The trend in the decrease of caffeine content is supported with the findings of $[12,15]$ showed that the caffeine content changed throughout the various stages of black tea production. The decrease in caffeine levels during fermentation was related to the time and temperature of fermentation. [18, 19] studied that acid is the by-product of any fermentation process in tea, during this process linolenic, aldehyde are formed due to which tea is acidic in nature. These findings are in close contest of $[16,14]$ which reported that black tea chemical quality parameters varied with fermentation temperature period.

\section{Conclusion}

Fermentation is a major and important process of tea processing in which the aflavin and the arubigens are formed. From the result, it was concluded that a proper balance between the aflavin and the arubigens which is very necessary for quality and also depends upon the duration and temperature period of fermentation. It is also concluded from the experiment that fermentation duration, $120 \mathrm{~min}$ and temperature range, $20-21^{\circ} \mathrm{C}$ showed the best result regarding the overall quality of black tea.

\section{Authors' contributions}

Conceived, designed and performed the experiments: S Wahab, Analyzed the data: F Ullah \& MS Memon, Contributed reagents/ materials/ analysis tools: MK Khattak, L Hassan, Wrote the paper: F Ullah.

\section{References}

1. Willson KC \& Clifformd MN (2000). Botanical classification of black tea. Chap 2: 1-3.

2. Li X \& Zhu X (2016). Tea: Types, Production, and Trade. Reference Module in Food Science. Encyclopedia of Food and Health 279-282.

3. Jain NK (1999). Pharmacological function of tea, Pub. Aravali Int. (Pvt) Ltd New Dehli.

4. Taulo JL \& Sebitosi AB (2016). Material and energy flow analysis of the Malawian tea industry. Renewable and Sustainable Energy Reviews1337-1350.

5. Heck CI \& Gonzalez de ME (2009). 16 Teas and tea-based functional beverages. Functional and Speciality Beverage Technology 396-417.

6. Uliana VK, Arkadii ES, Alexandra VR, Ludmila MB \& Aregnaz AK (2015). The Concept of "Tea" in the Language Picture of the World (Based on Chinese and Russian Languages. Procedia-Social and Behavioral Sciences. The XXVI Annual International Academic Conference, Language and Culture 22: 215-223.

7. Johnsona JJ, Baileyb HH \& Mukhtarc H (2015). Green tea polyphenols for prostate cancer chemoprevention: A 
translational perspective. Phytomedicine 17(1): 3-13.

8. Prabhakaran NKP (2010). The Agronomy and Economy of Important Tree Crops of the Developing World. 9 - Tea (Camellia sinensis L.) 275-300.

9. Harunur RMd, Alamgir ZCM, Zeenath F, Tanvirb EM, Kamruzzaman PM, Israt J, Khorshed AMd, Mohammed M \& Siew HG (2016). Microbial decontamination of gamma irradiated black tea and determination of major minerals in black tea, fresh tea leaves and tea garden soil. LWT - Food Science and Technology.

10. Verbrauch ZV (2001). Imports of tea for consumption. Tea cultivation to Consumption. Chap (7): 205-207.

11. Hamid FS (2004). Tea cultivation in Pakistan. Pakistan Agricultural Research Council, Islamabad 12(4): 127.

12. Martin O, Phillip O \& Taylor JS (1996). Chemical composition of some Kenyan black teas and their probable benefits to human health. NR Inst Overseas Dev Agency UK 17(1): 20-26.
13. UTRS (2002). Brochure of Unilever tea research station UTRS Shinkiari.

14. Nick H (2000). 1-The history and origins of tea. The Tea Industry 1: 1-19.

15. William S, Othieno CO \& Carr MKV (1992). Climate and weather variability at the Tea Research Foundation of Kenya. Agricultural and Forest Meteorology 61(3-4): 219-235.

16. Owour PO \& Obanda M (2001). Comparative responses in plain black tea quality parameters of different tea clones to fermentation temperature and duration. Food Chemistry 72(3): 319327.

17. Owour PO, Obanda M, McLean G \& Kisinyo PO (1999). Fermentability variatioins of popular clones from Nandi Hills, Kenya. Tea 20(1): 5-11.

18. Lee J (2003). Chapter 6 - The lure of tea: history, traditions and attractions. Food Tourism Around the World Development, management and markets 121-136.

19. Taylor S (2003). TEA Types, Production, and Trade. Encyclopedia of Food Sciences and Nutrition (Second edition) 5737-5743. 